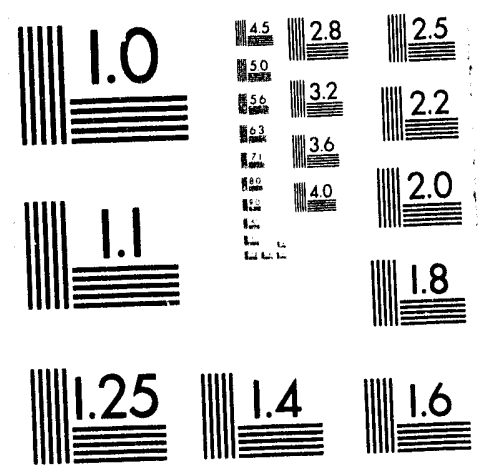



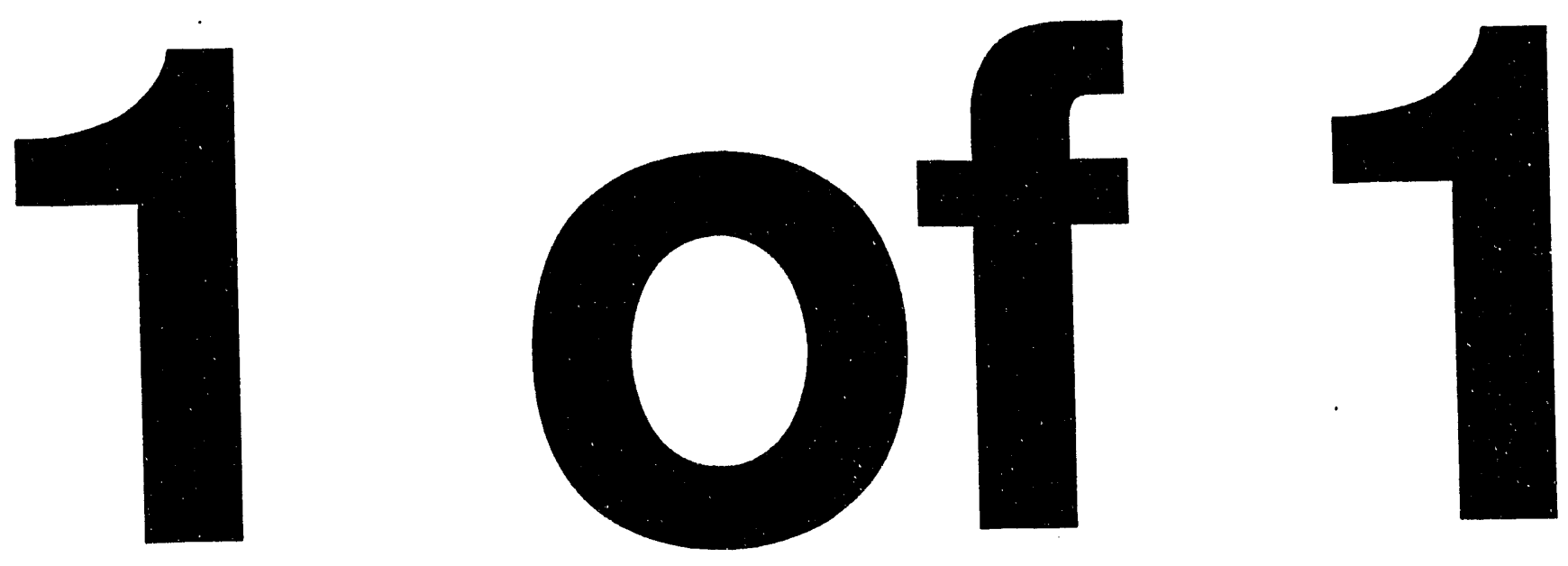
1.1

LA-UR, $94-1100$

TITLE: AN OPTIMAL TARGET-FILTER SYSTEM FOR ELECTRON BEAM GENERATED X-RAY SPECTRA

AUTHOR(S): HSIAO - HUA HSU, ESH-4

DENNIS G. VASILIK, ESH-4

JING CHEN, (GSF GERMANY)

SUBMITTED TO: HEALTH PHYSICS SOCIETY ANNUAL MEETING SAN FRANCISCO

JUNE 26-30, 1994

\section{DISCLAIMER}

This report was prepared as an account of work sponsored by an agency of the United States Government. Neither the United States Government nor any agency thereof, nor any of their employees, makes any warranty, express or implied, or assumes any legol liability or responsibility for the accuracy, completeness, or usefulness of any information, apparatus, product, or process disclosed, or represents that its use would not infringe privately owned rights. Reference herein to any specific commercial product, process, or service by trade name, trademark, manufacturer, or otherwise does not necessarily constitute or imply its endorsement, recommendation, or favoring by the United States Government or any agency thereof. The views and opinions of authors expressed herein do not necessarily state or reflect those of the United States Government or any agency thereof. 


\title{
AN OPTIMAL TARGET-FILTER SYSTEM FOR ELECTRON BEAM GENERATED X-RAY SPECTRA
}

\author{
Hsiao-Hua Hsu and Dennis G. Vasilik \\ Health Physics Measurement Group \\ Los Alamos National Laboratory \\ Los Alamos, NM 87545 U. S. A. \\ Jing Chen \\ Institut fur Strahlenbiologie \\ GSF, Postfach 1129, Neuherberg \\ 87578 Oberschleisshaim, Germany
}

\begin{abstract}
An electron beam generated $x$-ray spectrum consists of characteristic $x$ rays of the target and continuous bremsstrahlung. The percentage of characteristic $x$ rays over the entire energy spectrum depends on the beam energy and the filter thickness. To determine the optimal electron beam energy and filter thickness, one can either conduct many experimental measurements, or perform a series of Monte Carlo simulations. Monte Carlo simulations are shown to be an efficient tool for determining the optimal targetfilter system for electron beam generated $x$-ray spectra. Three of the most commonly used low-energy $\mathrm{x}$-ray metal targets $(\mathrm{Cu}, \mathrm{Zn}$ and Mo) are chosen for this study to illustrate the power of Monte Carlo simulations.
\end{abstract}

\section{INTRODUCTION}

Electron beam generated $x$ rays have been used extensively as sources for $x$ ray research, radiation biology research, and $x-r a y$ detector and dosimeter calibrations. With the proper selection of a target material, the $x$ ray energy can be varied from a few kev to about $120 \mathrm{keV}$. The $\mathrm{x}$ ray spectrum consists of two distinct portions: the characteristic $K$ and $L x$ rays of the target, and $a$ continuous bremsstrahlung spectrum with an energy up to the maximum electron beam energy. For research applications and detector or dosimeter calibrations, one often uses mono-energetic $x$ rays as the source. A filter is used to attenuate the bremsstrahlung background as much as possible, without a significant loss of the characteristic $x$ rays. The ratio of the $x$ ray to the total photon production is defined as the purity of $x$ ray source. The purity is a function of the electron beam energy and the filter thickness. To determine the optimal conditions for producing $x$ rays, one can either conduct extensive experimental measurements or perform Monte Carlo simulations. 
Since the bremsstrahlung production is proportional to $\mathrm{Z}^{2}$ (where $Z$ is the atomic number of target), and the ionization cross section is proportional to $z$, the $x$ ray production by diract electron beam bombardment is suitable only for low $z$ elements. Characteristic $x$ ray production with high $z$ targets utilizes photons to excite the target atoms where the source photons are produced by the electron bremsstrahlung process.

In this article, we study several low $\mathrm{z}$ metal target-filter systems. The calculations for high $\mathrm{z}$ target-filter systems will be presented in a separate article.

\section{MONTE CARLO SIMULATIONS}

The Monte Carlo code ACCEPTP ${ }^{1}$ of the Integrated TIGER series was used to perform the simulations. The physics, code structure, and various applications had been described in detail in articles by Halbleibl. Version 3 of the code is utilized because the production of $K$ and $L x$ rays are specifically tallied.

The experimental geometry is shown in Figure 1a. The metal target is placed at 45 degree to the incoming electron beam. The exit port is perpendicular to the electron beam. The exit port consists of a $0.0127 \mathrm{~cm}$ Be window and filter. The model geometry for simulation is shown in Figure 1b. The thin metal target $(0.0127 \mathrm{~cm})$, is surrounded by two metal shells corresponding to the window and filter. The photon spectra are tallied every 10 degrees.
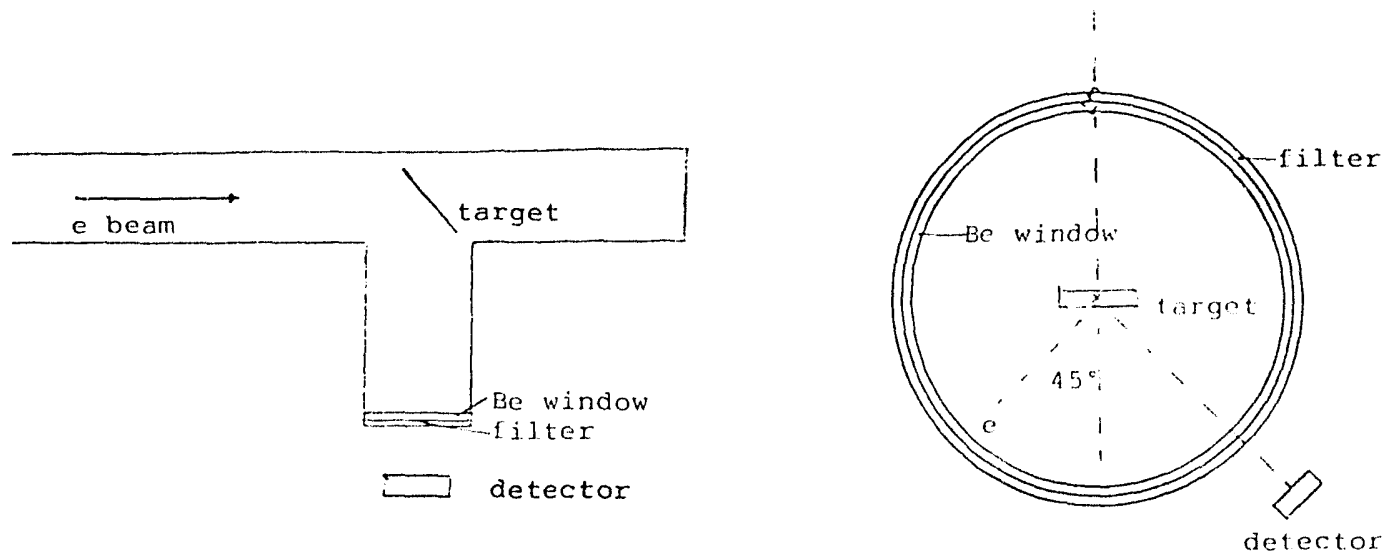

(a) Experimental setup.

(b) Model Geometry.

Figure 1. 
III. CHOICE OF FILTER

For a metal target with atomic number $\mathrm{z}$, the choice of filter material is based on the following considerations:

1. The filter material has a $K$ absorption edge energy either slightly higher than the energy of the $\mathrm{K}_{\beta}$ line or between the $\mathrm{K}_{\alpha}$ and $\mathrm{K}_{\beta}$ lines of the target material. Thus, the filter can be either the target material or element of $\mathrm{z}-1$.

2. The filter material can be either in a metal form or stable chemical form.

For illustration, consider two target-filter combinations of a $\mathrm{Cu}$ target with $\mathrm{Ni}$ filter and a $\mathrm{Cu}$ target with $\mathrm{Cu}$ filter. Table 1 lists the $\mathrm{K} \times$ ray energies for $\mathrm{Ni}$ and $\mathrm{Cu}$.

Table 1, K X Ray Energies for Nickel and Copper Energy (kev)

$$
\mathrm{Ni}(\mathrm{Z}=28) \quad \mathrm{Cu}(\mathrm{Z}=29)
$$

$\begin{array}{lll}\mathrm{K} \text {-edge } & 8.3318 & 8.9779 \\ \mathrm{~K}_{\alpha 1} & 7.4718 & 8.0399 \\ \mathrm{~K}_{\alpha 2} & 7.4548 & 8.0199 \\ \mathrm{~K}_{\beta} & 8.2640 & 8.9175\end{array}$

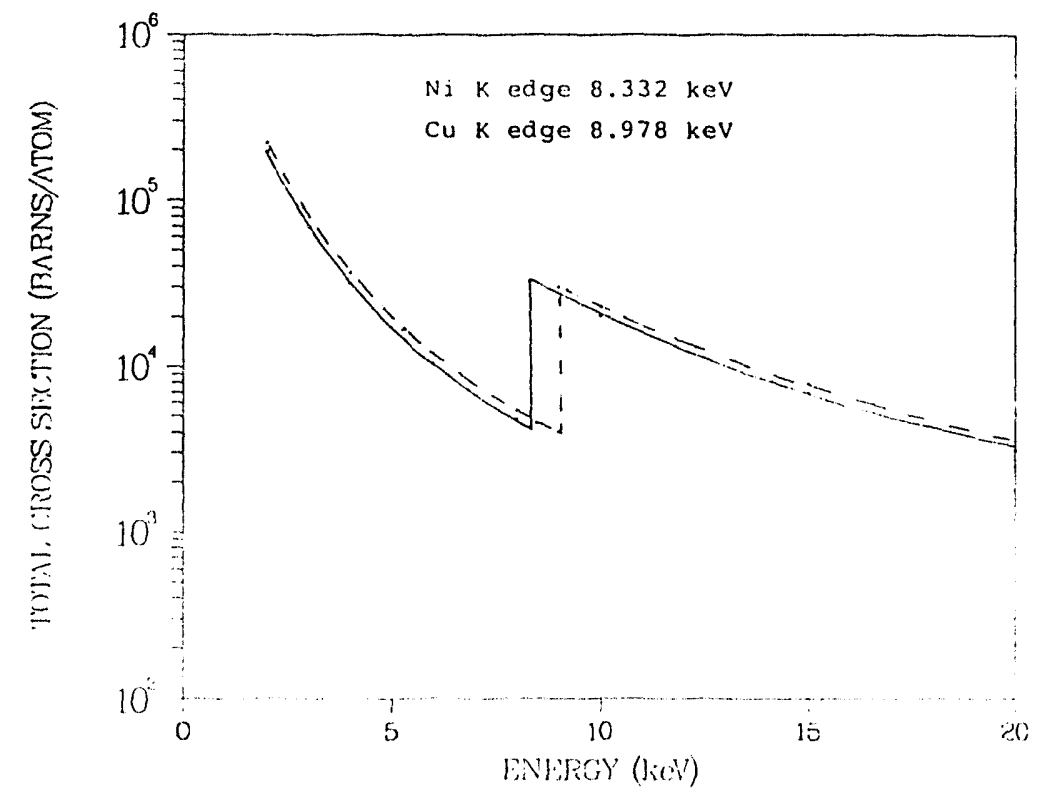

Figure 2. Photon Cross-Sections: $\mathrm{Ni}$ (solid), $\mathrm{Cu}$ (dash)

Figure 2 shows the photon interaction cross sections of $\mathrm{Ni}$ and $\mathrm{Cu}$. The energy of the $\mathrm{Cu} \mathrm{K}_{\beta}$ line is slightly higher than the $\mathrm{Ni} \mathrm{K}$-edge. The $\mathrm{Cu} \mathrm{K}_{\beta}$ will be highly attenuated, exciting the $\mathrm{Ni}$ atoms to produce $\mathrm{Ni} x$ rays. The final spectrum will consist of three $\mathrm{Ni} \times$ 
ray lines and two $\mathrm{Cu} \mathrm{K}_{\alpha}$ lines on a reduced continuum. The $\mathrm{x}$ rays energies are from $7.45 \mathrm{keV}$ to $8.26 \mathrm{keV}$. For a $\mathrm{Cu}$ target with a $\mathrm{Cu}$ filter, the filter will attenuate both the $K_{\alpha}$ and $K_{\beta}$ lines, with more effective attenuation on the higher energy side of the bremsstrahlung spectrum. The final spectrum consists of three $\mathrm{Cu}$ $x$ ray lines on a reduced continuum. The $x$ ray energies are from $8.02 \mathrm{keV}$ to $8.92 \mathrm{keV}$. For detector calibrations, a low energy $x$ ray detector, with an energy resolution of $0.5 \mathrm{keV}$, can resolve the $\mathrm{Cu} \mathrm{K}_{\alpha}$ and $\mathrm{K}_{\beta}$ lines, but will not easily resolve the $\mathrm{Ni} \mathrm{K} \times$ rays from the $\mathrm{Cu} \mathrm{K} \times$ rays.

\section{ANGULAR DISTRIBUTION}

The bremsstrahlung has a forward angular distribution. The characteristic $x$ rays are distributed isotropically. Because of the finite thickness of the target, the forward $x$ rays are absorbed by the target itself. Figure 3 shows a typical angular distribution of the $x$ rays.

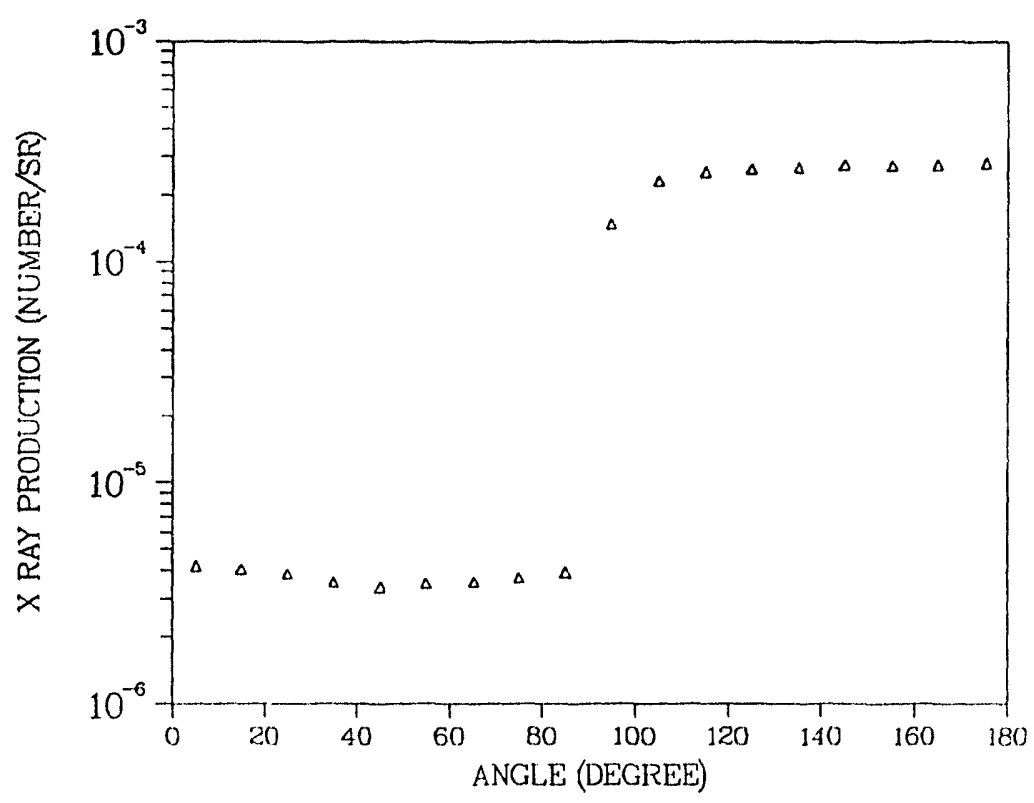

Figure 3. X Ray Angular Distribution

V. RESULTS

\section{A. Electron Beam Energy}

Figure 4 shows the number of $x$ rays at 135 -degree as a function of electron beam energy for all three targets. In the energy range of interest, the $x$ ray production increases almost linearly with beam energy. All targets generate very high yields. For example, for a $\mathrm{Cu}$ target at $100 \mathrm{kV}$, one electron produces $1.2 \times 10^{-3} \quad \mathrm{~K}_{\alpha} \times$ rays per steradian $(s r)$. Thus for a machine of $1 \mathrm{ma}$ current, $7.5 \times 10^{9} \mathrm{~K}_{\alpha} \times$ rays per msr per sec will be produced. 


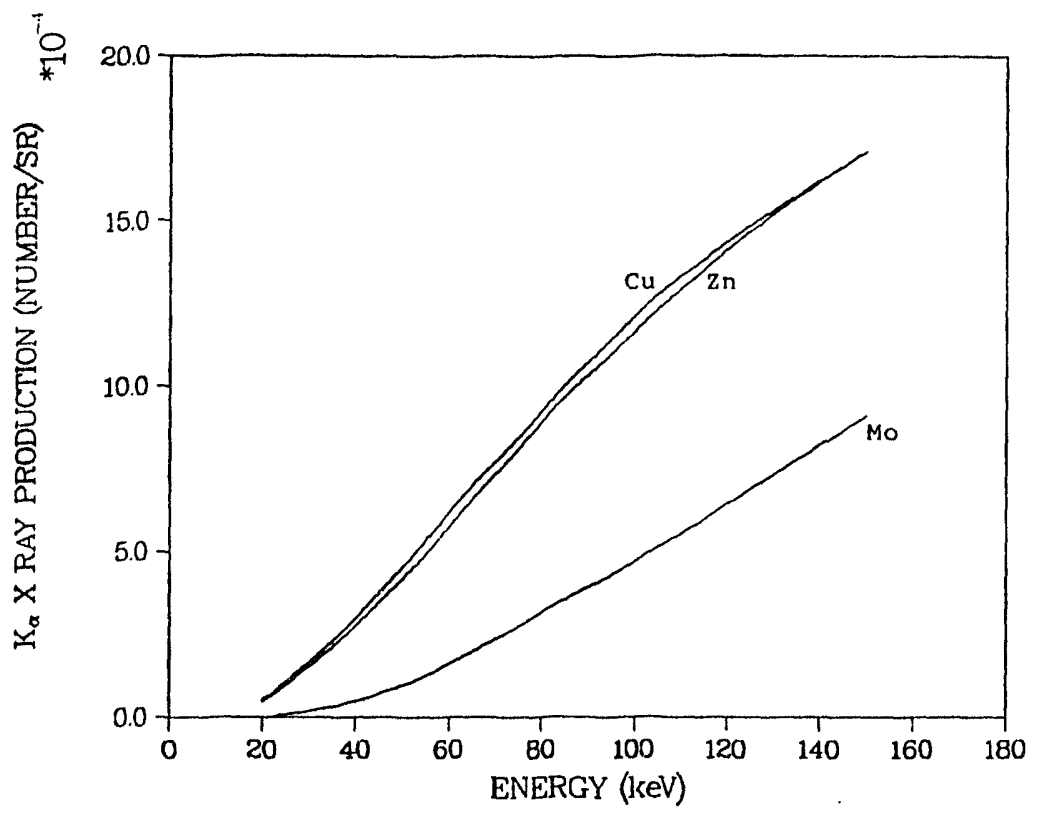

Figure $4 . \mathrm{K}_{\alpha} \mathrm{X}$ Ray Production as a Function of Electron Beam Energy

Figure 5 shows the $k_{\alpha} \times$ ray purity at 135 -degree as a function of electron beam energy for all three targets. Mo has a lower purity as compared with $\mathrm{Cu}$ and $\mathrm{zn}$ targets, because of the higher bremsstrahlung production.

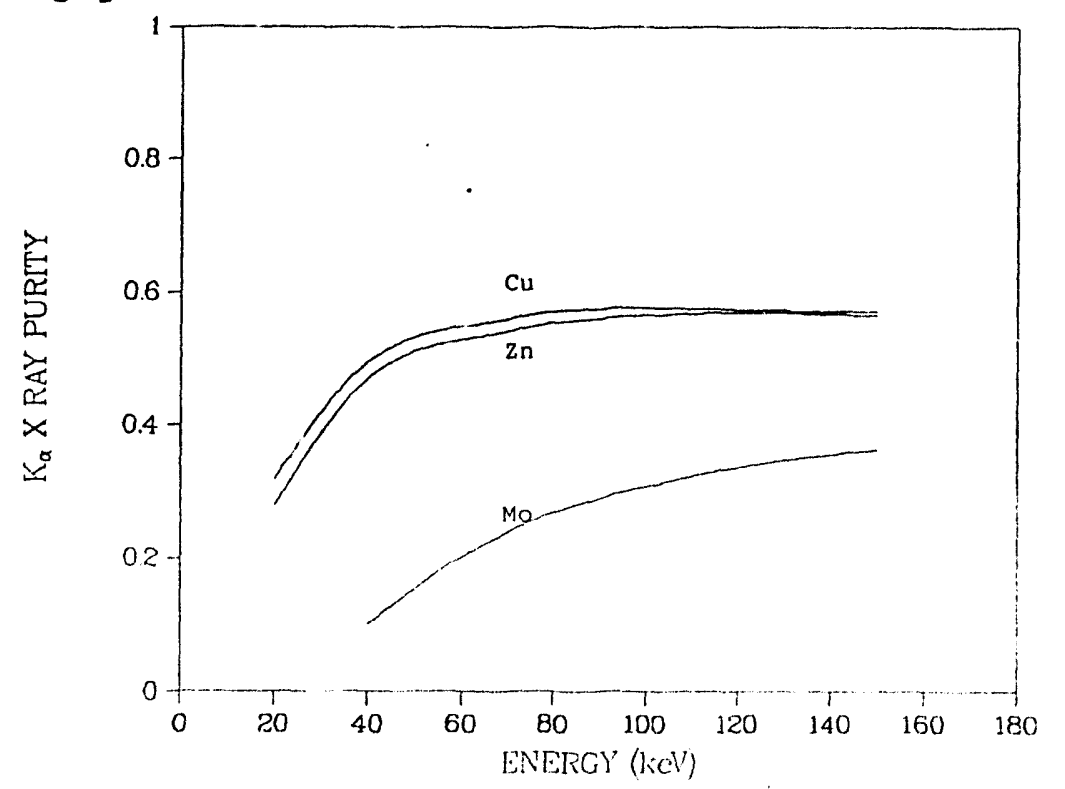

Figure 5. $K_{\alpha} X$ Ray Purity as a Function of Electron Beam Energy

B. Filter Thickness

1. Cu Target 
Figure 6 shows the purity of $K_{\alpha} \times$ rays from a $C u$ target at 135-degrees as a function of filter thickness for both $\mathrm{Ni}$ and $\mathrm{Cu}$ filters. The solid lines are for an electron beam energy of $50 \mathrm{kev}$, and the dashed lines are for $100 \mathrm{keV}$. Without a filter, the 100 $\mathrm{keV}$ beam generates a higher purity of $\mathrm{k}_{\alpha} \mathrm{x}$ rays. But with proper choice of filter ( $\mathrm{Ni}$ foil with thickness between 15 to $20 \mu \mathrm{m}$ ), the $50 \mathrm{keV}$ beam produces $K_{\alpha} \times$ rays with a purity of $65 \%$. The plots also show that an improper filter thickness not only reduces the intensity of $\mathrm{K}_{\alpha} \times$ rays, but also reduces the purity.

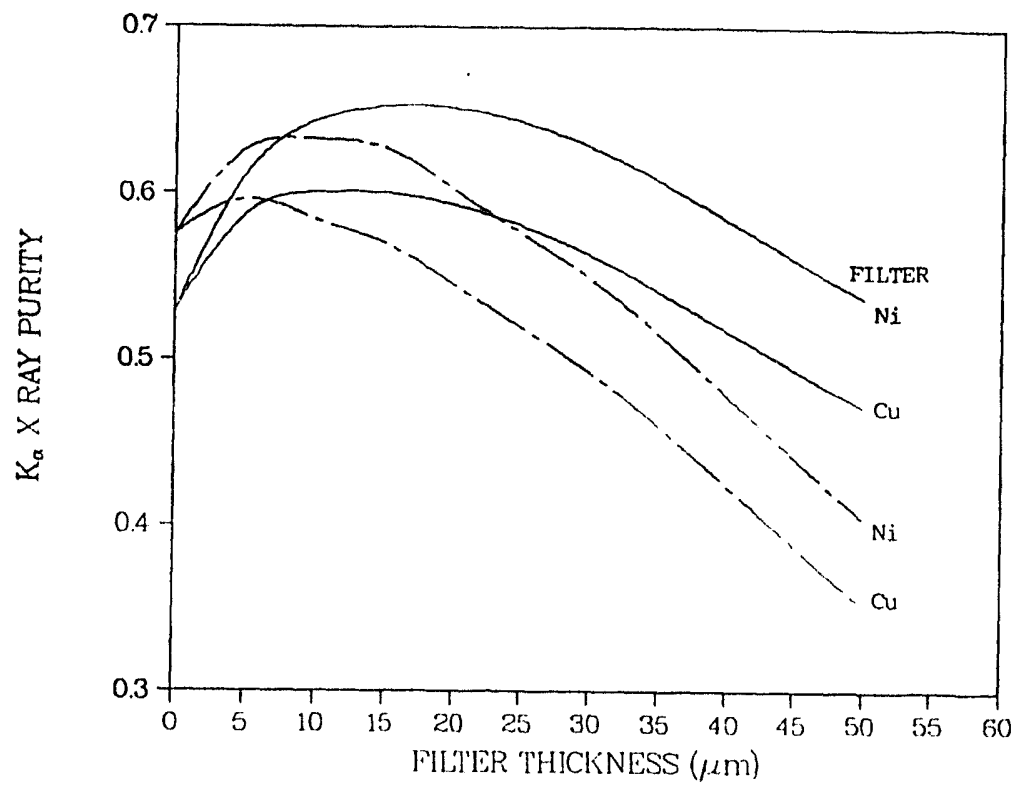

Figure 6. $\mathrm{Cu} \mathrm{K}_{\alpha} \mathrm{X}$ Ray Purity as a Function of Filter Thickness, at $135^{\circ}$ with Electron Beam Energies of $50 \mathrm{keV}$ (solid) and $100 \mathrm{keV}$ (dash).

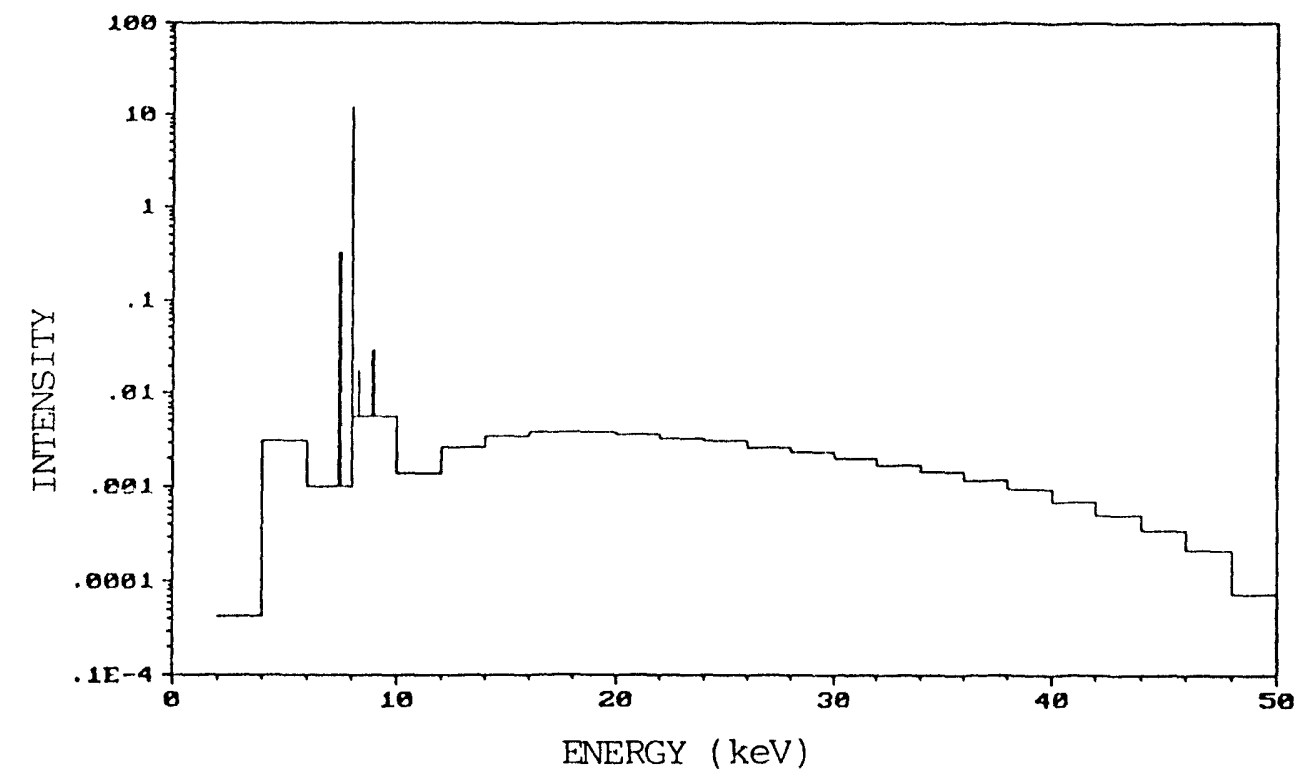

Figure 7. X Ray spectrum. Four lines are $\mathrm{K}_{\alpha}$ and $\mathrm{K}_{\beta}$ of $\mathrm{Cu}$ and $\mathrm{Ni}$. 
Figure 7 shows the photon spectrum produced by $50 \mathrm{kV}$ electron beam at 135-degree with a $15 \mu \mathrm{m} \mathrm{Ni}$ filter. These four lines are (from left to right) $\mathrm{Ni} \mathrm{K}_{\alpha}(7.47 \mathrm{keV}), \mathrm{Cu} \mathrm{K} \mathrm{K}_{\alpha}(8.04 \mathrm{keV}), \mathrm{Ni} \mathrm{K} \mathrm{K}_{\beta}(8.26$ $\mathrm{keV})$ and $\mathrm{Cu} \mathrm{K}_{\beta}(8.91 \mathrm{keV})$ respectively.

\section{2. $\mathrm{Zn}$ and Mo Targets}

Similar calculations were performed for $\mathrm{Zn}$ target with $\mathrm{Cu}$ or $\mathrm{Zn}$ as the filter and a Mo target with $\mathrm{Nb}$ or Mo as the filter. The results are shown in Figures 8 and 9. For a $\mathrm{Zr}$ target, the optimal thickness of the $\mathrm{Cu}$ filters are $20 \mu \mathrm{m}$ for a $50 \mathrm{kV}$ electron beam, and $10 \mu \mathrm{m}$ for a $100 \mathrm{kV}$ electron beam. They yield $64.4 \%$ and $63.3 \%$ purities respectively.

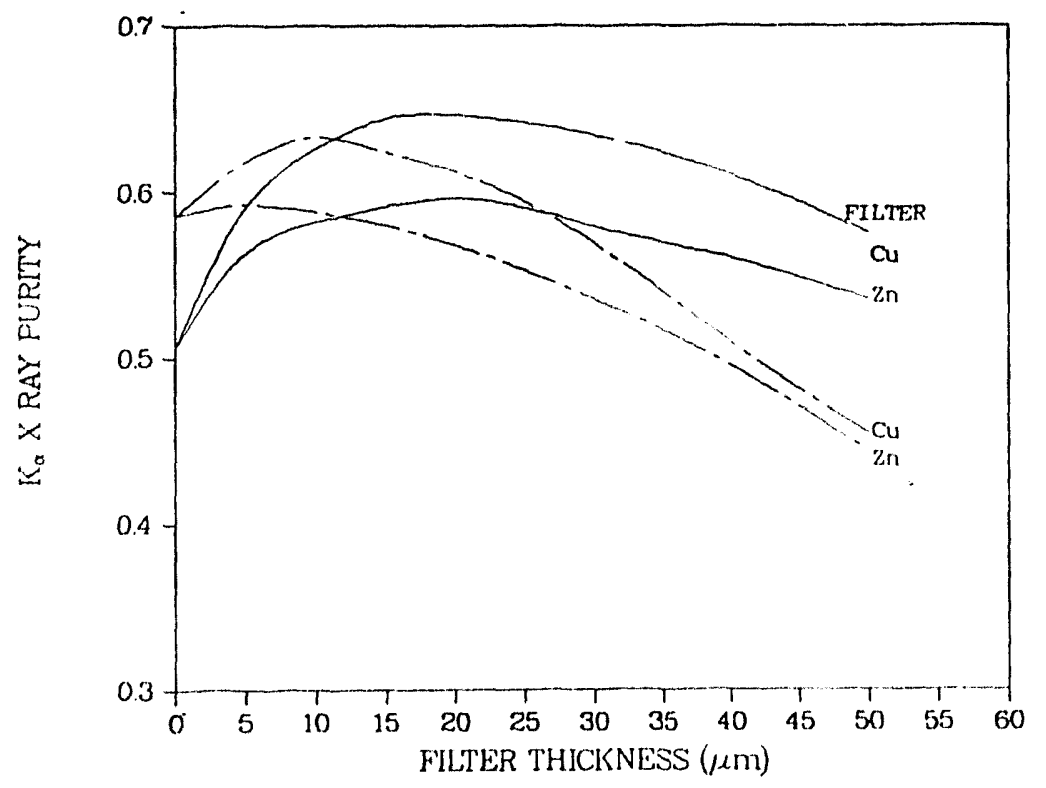

Figure 8 . The same as Figure 6 , but for a $\mathrm{Zn}$ Target.

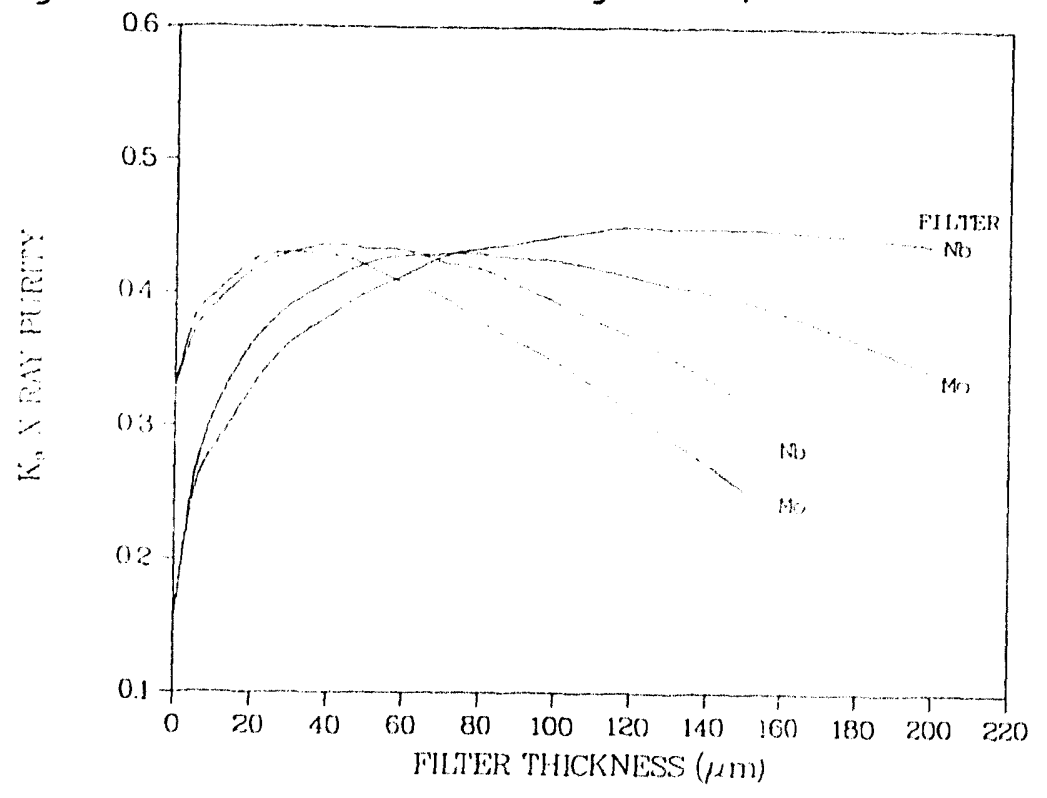

Figure 9. The same as Figure 6, but for a Mo Target. 
For a Mo target, as we expected, the bremsstrahlung production is much higher, and we achieve lower purities with both $\mathrm{Nb}$ and Mo filters. With a $\mathrm{Nb}$ filter, the optimal thickness is $120 \mu \mathrm{m}$ for a 50 $\mathrm{kV}$ electron beam and a $44.9 \%$ purity, and $40 \mu \mathrm{m}$ for a $100 \mathrm{kV}$ electron beam and a purity of $43.6 \%$.

VI. CONCLUSION

Monte Carlo simulations can be used to determine the optimal target-filter combination for characteristic $x$ ray productions. Further, the simulation can also determine the number of $x$ rays produced. Thus is important for the absolute efficiency calibration of detectors. The continuous bremsstrahlung and characteristic $x$ ray spectrum is important for dosimeter response function calculations ${ }^{2}$.

\section{REFERENCES}

1. J. Halbleib, "The Integrated TIGER Series", Chapters 10 and 11 , in "Monte Carlo Transport of Electrons and Photons", edited by T. M. Jenkins, W. R. Nelson and A. Rindi, Plenum Press, 1988 .

2. H. H. Hsu, R. C. Gooley and D. G. Vasilik, "Monte Carlo Simulations of the Low-Energy Photon Response for the Lus Alamos TLD Badge" "Third Conference on Radiation Protection and Dosimetry, orlando, Florida, Oct. 1991, Los Alamos National Laboratory report LA-UR-91-1171. 

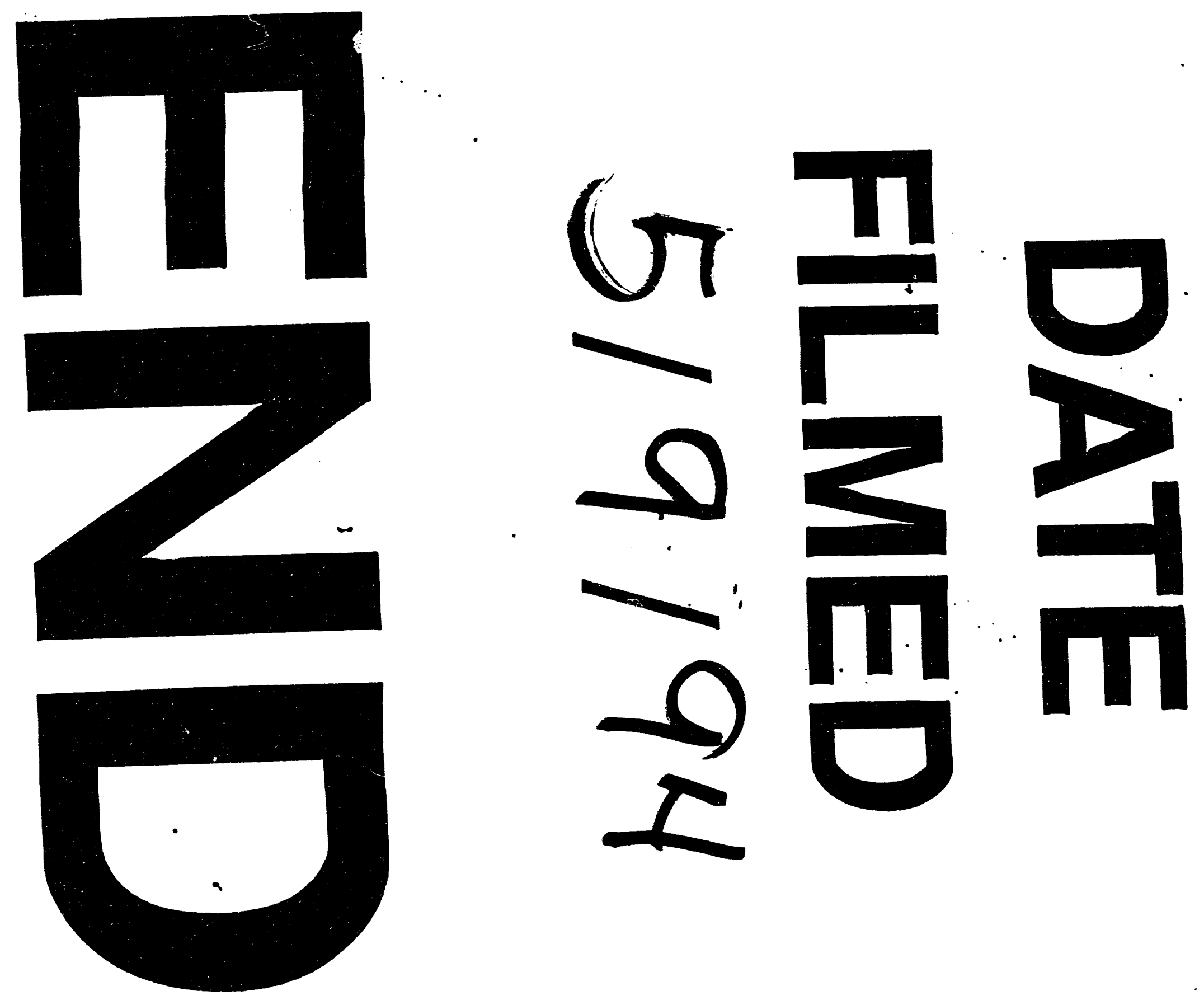
